\title{
Hierarchical composites with high-volume fractions of carbon nanotubes: Influence of plasma surface treatment and thermoplastic nanophase-modified epoxy
}

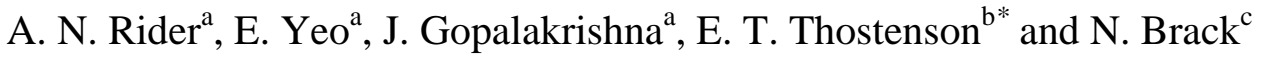 \\ a'Defence Science and Technology Organization, Fisherman's Bend, Victoria 3207,
} Australia

andrew.rider@dsto.defence.gov.au

${ }^{\mathrm{b}}$ Department of Mechanical Engineering, Department of Materials Science and Engineering, and Center for Composite Materials, University of Delaware, Newark, DE 19716, USA

thosten@udel.edu

cDepartment of Physics, La Trobe University, Victoria, 3086, Australia

n.brack@latrobe.edu.au

\begin{abstract}
A scaled-up catalytic chemical vapor deposition synthesis approach has been used to grow carbon nanotubes (CNTs) onto quartz and alumina fibers to prepare novel hierarchically structured composites with high volume fractions of CNTs. The assynthesized CNT-coated fibers were functionalized using atmospheric oxygen plasma, prior to infusing an epoxy polymer matrix, in order to improve wettability and bonding. The polymer matrix was further modified by adding a triblock copolymer to provide nanoscale toughening. Direct adhesion tests show that CNT and plasma treatments increase the shear strength of quartz or alumina/epoxy films by $30 \%$. CNT-quartz/epoxy composites show an $80 \%$ increase in the in-plane shear strength while the CNTalumina/epoxy composites show more than a three-fold increase in shear strength. The failure mechanisms of the films and the fiber composites are dominated by fracture through the catalytic iron nanoparticles and the improvements are limited by the CNT to fiber adhesion. The composites also have very high in-plane electrical conductivity,
\end{abstract}

\footnotetext{
*Corresponding author. Tel: 1-302-831-8789. Email: thosten@udel.edu (Erik Thostenson)
} 
over $3 \mathrm{~S} / \mathrm{cm}$. The carbon nanotubes form a piezoresistive sensing network surrounding the fibers. Under flexural loading the change in electrical resistance can detect damage initiation and impending fracture, particularly for the alumina composites.

\section{Introduction}

Hierarchical composite structures may be manufactured by integrating nanoscale reinforcements into traditional fiber-reinforced polymer composite (FRP) laminates. The nanoscale reinforcement is capable of occupying the interstitial regions created by the micro-scale fiber architecture, thereby creating a complex hierarchical structure with length scales spanning several orders of magnitude [1-3]. The mechanical properties of FRPs rely critically on the stress-transfer mechanisms at the interface between the fiber and matrix. This is affected by a number of factors including interfacial adhesion, wettability, matrix stiffness and fracture toughness [4,5]. Consequently, integration of nanomaterials such as carbon nanotubes (CNTs) provides the ability to manipulate this critical fiber-matrix interphase region to enhance mechanical or electrical properties of the composite structure for specific applications.

A wide range of processing methods have been employed to create hierarchical structures using CNTs such as chemical vapor deposition (CVD), in which CNTs are grown directly onto the reinforcing fiber prior to resin infusion [6-9]. Alternatively, the CNTs can be dispersed into the polymer matrix followed by infusion into the fiber bundles $[10,11]$ or the CNTs can be electrophoretically deposited (EPD) onto the reinforcing fabric prior to resin infusion [12,13]. More recently, direct spraying of CNTs onto resin pre-impregnated fabric has also been successfully employed to manufacture hierarchical carbon-epoxy composites [14].

Each of the processing methods has their individual strengths and weaknesses. The addition of CNTs to the resin prior to fiber infusion is relatively simple and provides flexibility in functionalization of the CNTs to optimize matrix adhesion but requires low loadings to prevent fabric filtering effects and high increases in resin viscosity. EPD offers the opportunity to engineer CNT-fiber and CNT-matrix adhesion [15] and can be applied directly to sized fibers, but it is difficult to control the orientation of the CNTs. CVD growth onto fibers can provide a very high density of perpendicularly aligned CNTs with good control over length and purity, reducing the need for processing of CNT mixtures to remove agglomerates or impurities. Often due 
to the high temperatures employed in CVD growth, the fibers can be damaged and strength may be degraded $[7,16]$, but more recent work has shown these problems can be reduced $[17,18]$. Nevertheless, additional processing of the CNTs after the CVD growth process may be required to improve CNT-matrix adhesion. It has been demonstrated that the CNT-fiber adhesion depends on the type of catalyst and fiber surface chemistry [9].

An additional benefit of incorporating CNTs into FRP laminates is the ability to manipulate the electrical properties. In the case of insulating fibers, such as glass or alumina, relatively small additions of CNTs can produce electrically conductive composites $[8,12,19]$ and improve thermal conductivity [20,21]. Additionally, it has been shown that the electrically conductive pathways formed by the CNTs are piezoresistive, providing the ability to detect the formation and accumulation of micro-scale cracks in situ [22-24].

In the current work the growth of CNTs has been examined onto quartz and alumina fibers using a catalytic CVD (CCVD) process. Whilst previous work examining the CVD approach has typically examined the properties of the hierarchical composite without CNT modification, this work has examined plasma functionalization to determine if improved chemical interaction with the matrix affects the composite mechanical performance. Additionally, the epoxy resin has been modified using a nanophase thermoplastic block copolymer to examine the effect of resin toughening. Existing work in the literature has looked at a lower modulus, higher failure strain resin but this was not modified with a nanophase thermoplastic [25]. In the previous work using EPD, the addition of a polyethyleneimine (PEI) thermoplastic was found to be critical to improving the mechanical performance of CNT-modified glass/epoxy composites [12]. By characterizing the influence of CVD growth on the two reinforcing fibers it is also possible to assess the influence of the CNT addition in terms of mechanical strength and how this relates to the piezo-resistive response. The study also provides a good comparison of the CVD and EPD methods for preparing hierarchical composites, where high-volume fractions of CNTs are used and functionalization and resin chemistry is manipulated to improve CNT-matrix adhesion and matrix toughness. 


\section{Experimental}

\subsection{Materials and processing}

Two different types of fibers were utilized as the primary reinforcement in the composite laminates, fused silica (Astroquartz ${ }^{\circledR}$ II, JPS Composites, USA) and alumina (Nextel ${ }^{\mathrm{TM}}$ 610, 3M Company, USA). The Astroquartz ${ }^{\circledR}$ II fused silica fabric is a plainweave fabric (style 525) and has an areal density of $67.8 \mathrm{~g} / \mathrm{m}^{2}$ and individual yarns made from 120 filaments with $9 \mu \mathrm{m}$ fiber diameters. Crystallisation or devitrification was reported to occur above $1050^{\circ} \mathrm{C}[26,27]$. The alumina fabric (Nextel $610 \mathrm{DF}-11 \alpha-$ $\mathrm{Al}_{2} \mathrm{O}_{3}$ ) is an 8-harness satin weave with an areal density of $373 \mathrm{~g} / \mathrm{m}^{2}$. The yarn is made from 400 filaments with $12 \mu \mathrm{m}$ fiber diameters. The Nextel 610 fibers are reported to retain up to $80 \%$ of their strength up to $1200^{\circ} \mathrm{C}[28,29]$. Adhesion studies used quartz glass and $\alpha$-alumina sheets (Goodfellows, UK) as substrates to grow CNTs and provide a planar representation of the fiber-matrix system.

The nanotoughened resin was prepared using Araldite LC 3600, which comprised bisphenol $\mathrm{A}$ and $\mathrm{F}$ epoxy resins combined with a mixture of diamine hardeners at 100:30 by weight (Huntsman, USA). A tri-block copolymer was added to the resin at $10 \%$ by weight using high-speed shear mixing over several hours, whilst maintaining the resin at $80^{\circ} \mathrm{C}$. The E21 triblock-SBM copolymer (Arkema, France) was a combination of polystyrene (PS), 1,4-polybutadiene (PB) and syndiotactic poly(methyl methacrylate) (PMMA) at an approximate weight ratio of 22, 9 and 69 for each block, respectively [30]. Effective dissolution of the E21 was characterised by the resin retaining a high degree of transparency to ambient light, before and after addition of the hardener, and following cure for 24 hours at $25^{\circ} \mathrm{C}$ and 4 hours at $80^{\circ} \mathrm{C}$.

\subsection{Carbon nanotube treatment}

A scaled-up $16 \mathrm{~L}$ quartz-tube reactor was used to grow the CNTs onto the fabric (Figure S1), which had a $115 \mathrm{~mm}$ diameter and a uniform heating length of $400 \mathrm{~mm}$. Astroquartz and Nextel fabric sheets of $400 \mathrm{~mm}$ x $250 \mathrm{~mm}(\mathrm{~L} \mathrm{x} \mathrm{W})$ were clamped to a metal frame prior to insertion in the reactor (Figure S2). CNTs were grown on the fabric by CCVD using a xylene-ferrocene feedstock in an argon/hydrogen atmosphere at $800^{\circ} \mathrm{C}$. The quantity of CNTs grown onto the fabric was estimated by weighing both the 
fabric and small coupons of quartz and alumina, which were placed throughout the reaction zone. The CCVD-grown CNTs have previously been characterized and the growth process optimized to maximize CNT purity, length and crystallinity in the scaled-up reactor $[31,32]$. In order to maintain consistency in processing conditions between the quartz and Nextel fabrics, similar treatment times between 30 and 60 minutes were used for CNT growth. Consequently, the fiber volumes were higher for the Nextel laminates due to slower growth rates and higher areal density of the fabric. Prior to laminate preparation, the CNT-treated fabric was plasma treated using an Atomflo ${ }^{\circledR} 500$ atmospheric plasma unit (Surfx Technologies, USA) at 200W with flowrates of $30 \mathrm{~L} / \mathrm{min}$ for helium and $1.5 \mathrm{~L} / \mathrm{min}$ for oxygen.

\subsection{Shear samples and laminate preparation}

Shear strength of the CNT-treated quartz and alumina planar substrates was assessed by infusing the CNT films with the nano-toughened resin and bonding a 12 $\mathrm{mm}$ diameter shear stub directly onto the film, followed by cure using the same conditions as the composite laminates. Laminates were prepared using a wet lay-up procedure using the CNT-treated fabric and nanotoughened resin at a 1:1 parts by weight ratio. Laminates typically comprised 12 sheets of CNT-treated fabric of $300 \mathrm{~mm}$ x $200 \mathrm{~mm}$ dimensions. The composites were cured under a static load of $50 \mathrm{kN}$ at $25^{\circ} \mathrm{C}$ for 24 hours, followed by a 4 hour post cure at $80^{\circ} \mathrm{C}$.

\subsection{Mechanical and electrical testing}

The fiber properties were measured using loose bundles containing 100-120 fibers that were removed from untreated and CNT-treated fabric, based on a modified ASTM D3379-75 method [33] with monofilament strength correction using the Coleman factor $[34,35]$. The adhesion strength of the CNT-treated quartz and alumina coupons infused with epoxy was measured by applying a torque to the bonded stub and measuring the load at failure. Fracture typically occurred at the planar substrate-film interface. The flexural strength was measured using the 4 point flexure test (ASTM D 6272 - 02) [36] with stiffness determined using a deflectometer (Model 3540, Epsilon, USA). The in-plane shear strength was determined based on ASTM D3846-02 [37] and the shear modulus, $\mathrm{G}_{12}$, was measured using $1 \mathrm{~mm} \times 0.7 \mathrm{~mm}(\mathrm{~L} \times \mathrm{W})$ biaxial-strain gauges (FCA-1-11-3L, TML, Japan) in the elastic region between $1500 \mu \varepsilon$ and $4500 \mu \varepsilon$. The 
laminate compositions were established from density measurements [38] and the weight of the CNT-treated fabric. The mechanical properties of the copolymer toughened resin were measured using thick-adherend lap-shear (ASTM D5656-04), tensile dog-bones (ASTM D638-03) and mode I long crack extension testing (modified ASTM D3433)

The electrical conductivity was measured using a four-wire technique (ASTM D257-07 39) using a Nanovolt/Micro-ohm meter to source a $10 \mathrm{~mA}$ current and measure the resulting voltage (HP34420A, Hewlett Packard, USA). Specimen edges were polished and coated with silver paint prior to application of electrodes using conductive silver epoxy resin. The changes in electrical resistance were also measured in real-time during mechanical testing of the flexural test samples to examine the piezoresistive response as well as examine the potential to sense the onset and accumulation of damage in the composites.

\subsection{Chemical characterization and failure analysis}

XPS (Kratos Nova, U.K.) was used to characterize the chemical treatments and shear fracture surfaces using a monochromatic $\mathrm{Al} \mathrm{K}_{\alpha, 1} \mathrm{X}$-ray source at $150 \mathrm{~W}$ with an analysis area of $700 \times 300 \mu \mathrm{m}^{2}$. Survey and region spectra were acquired with $160 \mathrm{eV}$ and $20 \mathrm{eV}$ pass energies, respectively. Spectra quantification and peak-fitting used CasaXPS software (Casa Software, UK.) with the Kratos sensitivity library and a Shirley background fit with a Gaussian/Lorentzian peak shape ratio of 30. Spectra were charge corrected to the $\mathrm{C} 1 \mathrm{~s}$ peak at 284.4 for $\mathrm{sp}^{2}$ bonding and $285.0 \mathrm{eV}$ for $\mathrm{sp}^{3}$ bonding. Calculated atomic concentrations typically have an error of $\pm 10 \%$ of the measured value. Depth profiles were performed using an argon-ion gun operated at 4 $\mathrm{kV}$ and $5 \times 10^{-8}$ Torr argon base pressure and a current density of $44 \mu \mathrm{a} / \mathrm{cm}^{2}$, which led to a calibrated sputter rate on $\mathrm{Ta}_{2} \mathrm{O}_{5}$ of $6 \mathrm{~nm} / \mathrm{min}$ [40]. SEM analysis (LEO 1530VP) of the fracture surfaces from the failed laminates and films used a $3 \mathrm{kV}$ accelerating voltage with a $1.5 \mathrm{~nm}$ Ir layer to prevent charging. Energy dispersive spectroscopy (EDS) and back-scattered electron (BSE) imaging were used to identify the metallic iron phases from fracture surfaces of failed CNT-treated quartz and alumina substrates.

\section{Results and discusssion}

\subsection{Material characterization}


Table 1 shows the mechanical properties of the epoxy resin toughened using the E21 nanophase block-copolymer. The results indicate that there is only minor stiffness reduction but improvement in the strain to failure and fracture toughness, consistent with previous work [30]. Cryogenically fractured resin (Fig. S3) shows that most nanophase micelles are less than $100 \mathrm{~nm}$ in diameter with failure characterized by cavitation of the internal PS and PB blocks [41], leading to fine filaments emanating from the cavities. The cavitation and matrix shear-yielding are believed to be responsible for the improvements in toughness. Given the small size of the nanophase micelles, the E21 copolymer toughened resin used in laminate manufacture should enable those micelles to penetrate the interstitial fiber regions of the CNT-modified fabrics.

Table 1 Mechanical properties for LC 3600 with addition of 10\% E21 SBM block copolymer indicating shear strength, $\tau_{\text {ult, }}$, shear strain at failure, $\gamma_{\text {ult }}$, tensile modulus, E, tensile strength, $\sigma_{\text {ult }}$, strain at failure, $\varepsilon_{\text {ult }}$, and mode I fracture toughness, $\mathrm{G}_{\mathrm{IC}}$.

\begin{tabular}{|c|c|c|c|c|c|c|c|c|c|c|c|c|}
\hline \multirow{2}{*}{$\begin{array}{l}\text { Resin } \\
\text { System }\end{array}$} & \multicolumn{2}{|c|}{$\tau_{\text {ult }}(\mathbf{M P a})$} & \multicolumn{2}{|c|}{$\gamma_{\text {ult }}$} & \multicolumn{2}{|c|}{ E (GPa) } & \multicolumn{2}{|c|}{$\sigma_{\text {ult }}(\mathbf{M P a})$} & \multicolumn{2}{|c|}{$\overline{\varepsilon_{\mathrm{ult}}}$} & \multicolumn{2}{|c|}{$\mathbf{G}_{\text {Ic }}\left(\mathbf{J} / \mathbf{m}^{2}\right)$} \\
\hline & $\mathrm{avg}^{1}$ & conf. $^{2}$ & avg & conf. & avg & conf. & avg & conf. & $\overline{\text { avg }}$ & conf. & avg & conf. \\
\hline LC 3600 & 42.1 & 1.0 & 0.35 & 0.02 & 4.8 & 0.5 & 70 & 6 & 0.035 & 0.008 & 330 & 100 \\
\hline $\begin{array}{l}\text { LC 3600+ } \\
10 \% \text { E21 }\end{array}$ & 38.8 & 0.7 & 0.77 & 0.14 & 4.4 & 0.6 & 77 & 7 & 0.040 & 0.009 & 878 & 109 \\
\hline \multicolumn{13}{|c|}{${ }^{1}$ average $^{2} 95 \%$ confidence limit for 5 samples } \\
\hline \multicolumn{13}{|c|}{ Following growth of the CNTs onto the fabrics, tensile testing shows the Nextel } \\
\hline \multicolumn{13}{|c|}{ fiber bundles have similar trends in modulus (Fig. 1) and strength (Fig. 2) with gauge } \\
\hline \multicolumn{13}{|c|}{ length irrespective of the treatment, suggesting the $\alpha-\mathrm{Al}_{2} \mathrm{O}_{3}$ was resistant to both the } \\
\hline \multicolumn{13}{|c|}{ high CVD temperatures and iron catalyst exposure. Measured values at $50 \mathrm{~mm}$ gauge } \\
\hline \multicolumn{13}{|c|}{ lengths approach the quoted monofilament value of $373 \mathrm{GPa}[29]$. The corrected bundle } \\
\hline
\end{tabular}


By contrast, the quartz shows a reduction in modulus (Fig. 1) and strength (Fig. 2), with the CNT growth decreasing the modulus and both the heat and CNT treatment reducing strength. The untreated quartz-fiber bundles have a corrected strength around 1 GPa at $20 \mathrm{~mm}$ gauge length, which corresponds to a Weibull modulus of 3.5 and a characteristic strength of $2.4 \mathrm{GPa}$, quoted for the monofilament [27]. There is a significant reduction in Weibull modulus for the heat and CNT treatments, reflecting the strength reduction and broader distribution. Previous research on CVD growth of CNTs onto Silfa ${ }^{\circledR}$ glass fibers has also noted a strength reduction [7], which was attributed to catalyst etching of the glass fiber, leading to increased surface defects. The reduced modulus observed for Astroquartz in Fig. 1 was not observed for the Silfa fibers, which may be due to increased treatment times and temperatures used in this work.

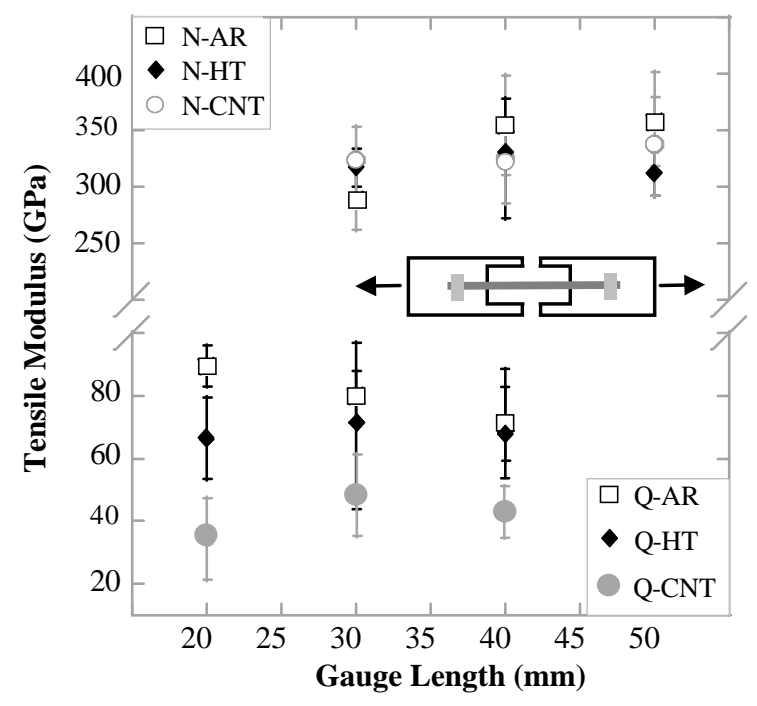

Fig. 1. Tensile modulus for different gauge length quartz $(\mathrm{Q})$ and Nextel $(\mathrm{N})$ fiber strands before (AR) and after heat treatment (HT) or 60 minutes CNT deposition (CNT) 


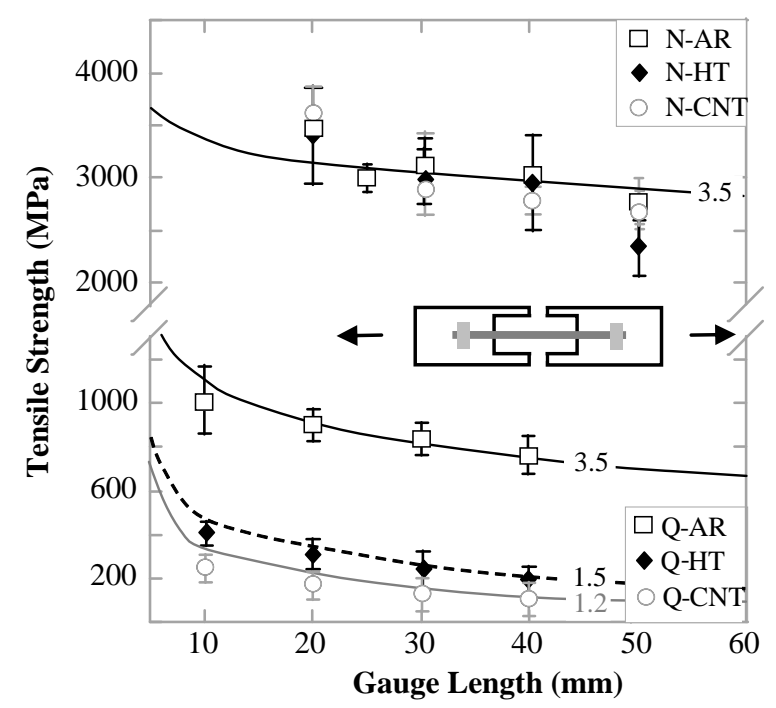

Fig. 2. Tensile strength for different gauge length Quartz (Q) and Nextel (N) fiber strands before (AR) and after heat treatment (HT) or 60 minutes CNT deposition (CNT). The strengths are corrected for bundle effects and the Weibull modulus used to fit the data is indicated.

The strength reduction caused by heating at $800^{\circ} \mathrm{C}$, even without $\mathrm{CNT}$ growth, suggests that a structural change has occurred in the Astroquartz. Potentially, the ambient storage of the heat-treated and CNT-treated fibers prior to testing has led to moisture exposure of the unprotected fibers and mechanical degradation, particularly when the bundles were removed from the fabric. Studies on sized-glass fibers exposed to moisture have also indicated clear stiffness reduction in the outer surface $[42,43]$. The absence of sizing and increased surface roughness and defects introduced by the CCVD processes could lead to increased susceptibility of the quartz to long-term moisture induced damage, which is known to occur with E-glass [44].

\subsection{CNT plasma treatment and interfacial film adhesion}

The CNT-films grown onto $\alpha$-alumina and quartz substrates were modified with oxygen plasma treatment to assess the effect of hydrophobicity of the CNTs on resin wetting. Table 2 shows that the plasma increases the oxygen content of the CNTs by around 10 atomic $\%$, corresponding to $\mathrm{C}-\mathrm{O}$ type groups and a reduction in $\mathrm{C} \mathrm{sp}^{2}$ graphitic character. The C 1s and valence band XPS spectra (Figs. S4-S5) also show the changes caused by plasma treatment. Previous studies using atomic-oxygen functionalization of CNTs also indicated formation of $\mathrm{C}-\mathrm{O}$ and $\mathrm{C}=\mathrm{O}$ type groups [45]. 
Table 2. Surface elemental composition of CCVD-grown CNTs before and after atmospheric oxygen plasma treatment

\% atomic concentration

\begin{tabular}{ccccccccc}
\hline Group/element & $\mathrm{C} \mathrm{sp}^{2}$ & $\mathrm{C} \mathrm{sp}^{3}$ & $\mathrm{C}-\mathrm{O}$ & $\mathrm{C}=\mathrm{O}$ & $\mathrm{O}-\mathrm{C}=\mathrm{O}$ & $\pi \rightarrow \pi^{*}$ & $\mathrm{O} 1 \mathrm{~s}$ & $\mathrm{Fe} 2 \mathrm{p}$ \\
\hline Binding energy $(\mathbf{e V})$ & 284.5 & 285.2 & 286.9 & 288.1 & 289.3 & 291.4 & 532.4 & 711.1 \\
\hline CNT as grown & 89.5 & --- & --- & --- & --- & 9.7 & 0.6 & 0.2 \\
\hline CNT + plasma & 61.3 & 12.4 & 7.2 & 1.2 & 0.5 & 6.4 & 10.6 & 0.3 \\
& & & & & & & & \\
\hline
\end{tabular}

The level and nature of oxidation in this work is similar to that achieved by a microwave-plasma exposure of 3 minutes [46]. This level of oxidation was also shown to lead to complete wetting of the CNT forests by water [46]. The benefit of the current plasma treatment is that it can be conducted under atmospheric conditions with excitedoxygen atoms providing an efficient and rapid oxidation step [47,48].

In order to directly examine the adhesion between the CNT film and quartz or alumina, CNT films were grown onto planar quartz and $\alpha$-alumina substrates to measure the interfacial shear strength. Shear-adhesion strength for the resin-infused CNT-films is shown in Figure 3. The shear strength without CNT treatment is around $40 \mathrm{MPa}$ for alumina and close to the interfacial shear strength (IFSS) values reported for single-fiber tests in which fiber/matrix debonding occurred [49]. 


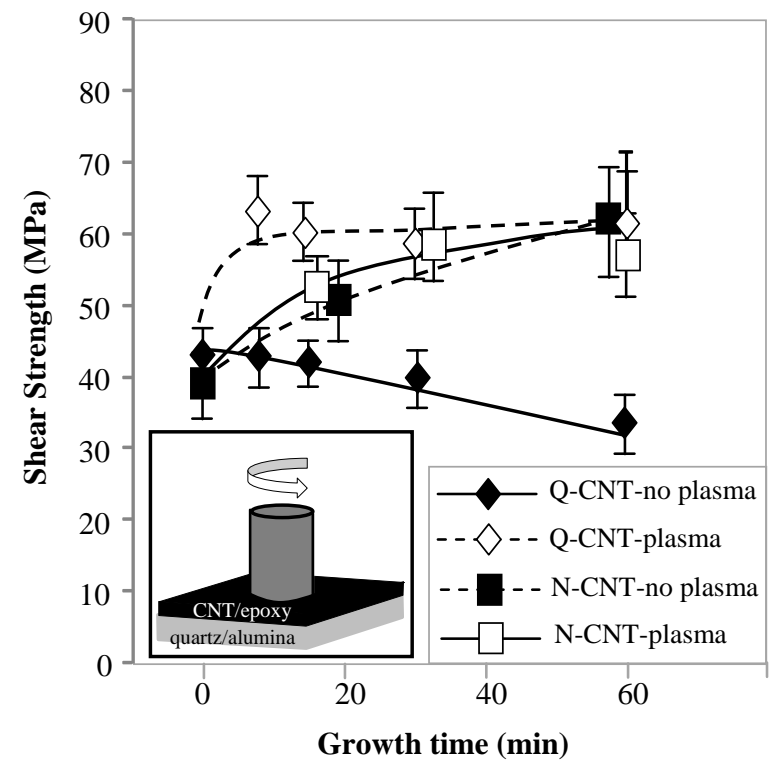

Fig. 3. Shear strength measured for CNT-films grown onto quartz (Q-CNT) and $\alpha$-alumina (NCNT) planar substrates followed by infusion with nano-toughened epoxy resin

Both the quartz and alumina-shear strengths increase as a result of the introduction of the CNT treatment by approximately $30 \%$. The CNT-film strength on alumina increases with increasing growth time but is not affected significantly by the plasma treatment. The CNT-film strength on quartz increases rapidly in strength for plasma treatment and reaches a consistent level, whereas, if no plasma treatment is applied, the strength progressively decreases as the film thickness increases. These results show that the CNT film on the quartz requires the plasma treatment to improve resin wettability. The more open structure of the CNT films grown on alumina as compared to quartz (see Fig. S6) may facilitate better wetting and infiltration without the need for plasma treatment, particularly for the thicker films.

SEM analysis of the fractured films in Fig. 4 show that failure occurs at the CNT-film and quartz substrate. The quartz substrates (Figs. $4 \mathrm{c}$ and $4 \mathrm{~d}$ ) show iron nanoparticles deposited during growth and columns of iron which have pulled out from the CNT bases during fracture (confirmed with EDS and BSE). The complementary CNT-infused resin fracture surfaces (Figs. $4 \mathrm{a}$ and $4 \mathrm{~b}$ ) show the high density of CNTs surrounded by resin, regions where CNTs have separated from the glass and some areas where CNT pull-out has occurred. At shorter growth times, the resin shows more evidence for cavitation. 


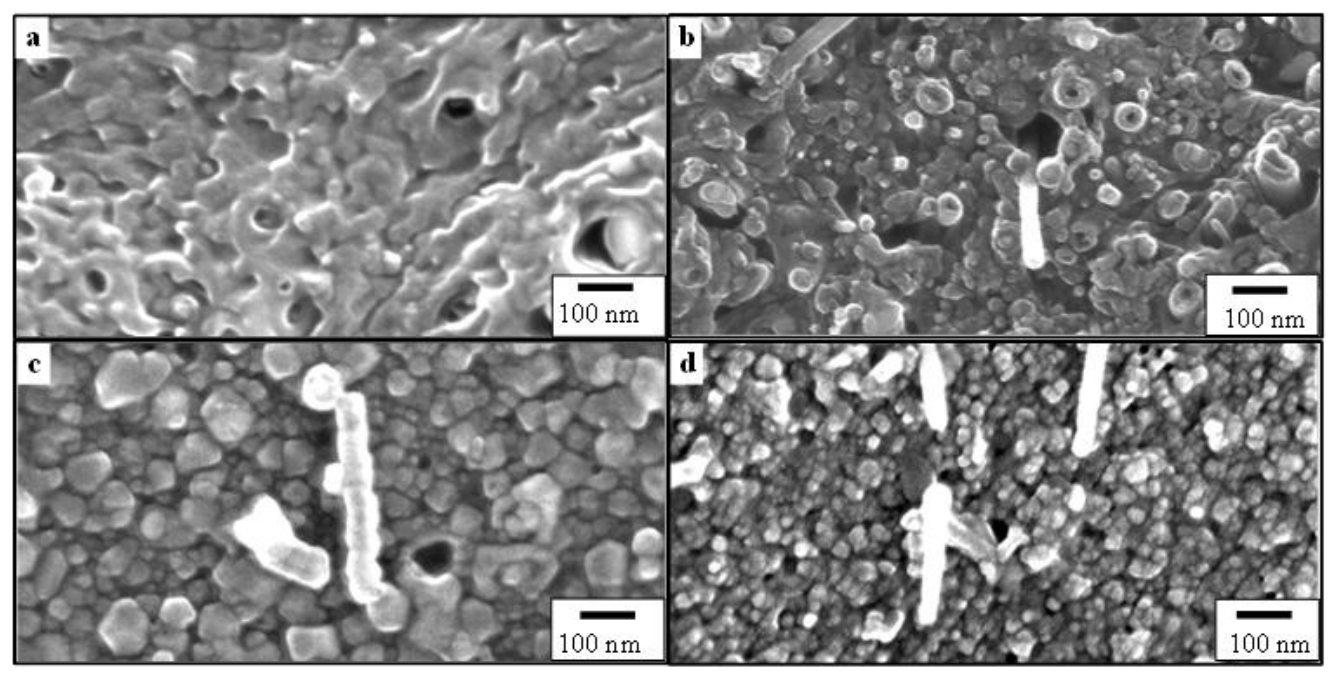

Fig. 4. SEM fracture surface images for epoxy-infused CNT-films grown on quartz resulting from shear failure indicating the CNT-epoxy coating for (a) $15 \mathrm{~min}$. and (b) $60 \mathrm{~min}$. growth time and the quartz substrate for (c) $15 \mathrm{~min}$. and (d) 60 min growth time.

The locus of fracture was confirmed by depth-profile analysis of the fracture surfaces (Fig. 5). The iron layer is estimated to be $30 \mathrm{~nm}$ thick, which is consistent with the average CNT diameter. The rapid decrease of carbon on the quartz side also shows that the epoxy that diffused through the CNT layer was unable to penetrate iron catalyst nanoparticle layer on the glass surface. The lower iron concentration on the coating side shows iron concentrated at the tube base within the CNTs and is approximately $30 \mathrm{~nm}$ in depth. Similar results were observed for the CNT-treated alumina substrates. The results suggest that the nanotoughened E21 resin can effectively wet the plasma treated CNT films, with the CNTs offering some improvement in adhesion and shear strength of the resin, which is around $40 \mathrm{MPa}$ (Table 1). Failure occurs due to debonding of the CNT-resin layer from the glass or alumina substrate.

As the shear load increases it appears that stress is concentrated at the region close to the CNT and glass or alumina interface, due to the higher density of CNTs and metalliciron nanoparticles. This would consequently increase stiffness and attract load. With the effectively reduced volume of toughened epoxy close to the interface it might be expected that crack development and propagation at the interface would be favored. The increased shear strength would indicate the adhesion of the CNTs and epoxy at the glass or alumina surface is still superior to the case without CNTs, but the high interfacial stiffness promotes fracture at the glass/CNT interface. This result is consistent with our 
previous research on adhesion of CNT films on glass using a polyethyleneimine dendrimer (PEI) for functionalization [15]. This work revealed that higher levels of PEI near the interface of CNT-treated glass epoxy samples increased strength by moving the fracture deeper into the interphase region and away from the glass surface. In the current work, control of the CNT density may offer a method to increase shear strength by moving fracture away from the glass or alumina-CNT interface.

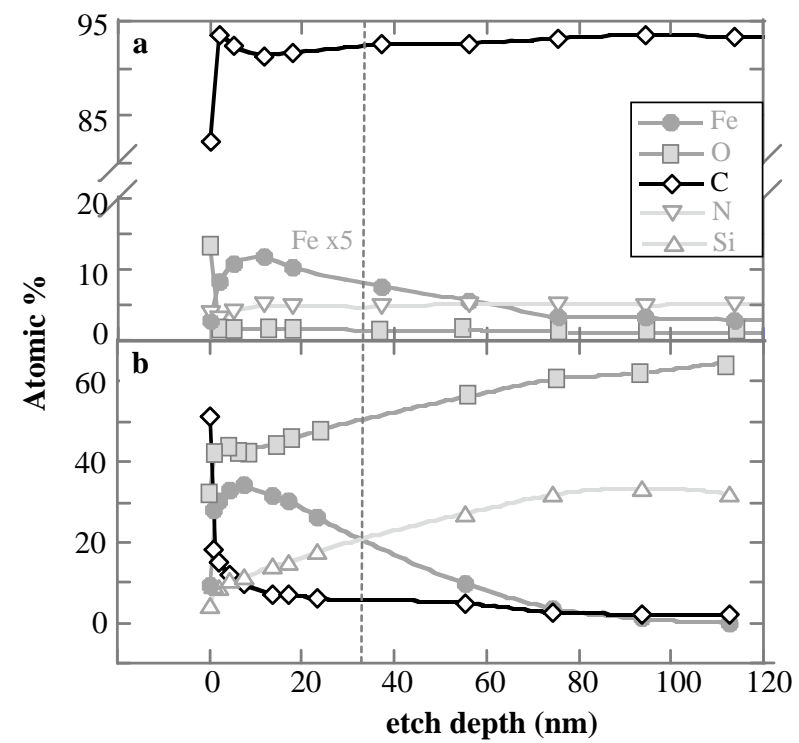

Fig. 5. XPS depth profile for epoxy infused CNT-film grown on a quartz substrate indicating the atomic \% with depth for the (a) coating and (b) quartz failure surfaces after shear testing

\subsection{Mechanical properties and fracture analysis}

\subsubsection{In-plane shear testing}

The shear modulus for the CNT-modified laminates is shown in Fig. 6. The modulus, $\mathrm{G}_{12}$, was predicted using the periodic microstructure model [50] and the same material properties used in the flexural modulus calculation (refer section 3.3.2), assuming isotropic fibers with Poisson ratios of 0.16 and 0.163 [51], for the quartz and Nextel fibers, respectively. The quartz laminate $G_{12}$ values (Fig. 6a) are close to values expected and show a considerable increase in stiffness expected for the high-volume fraction of CNTs, approaching $26 \%$ in the matrix $\left(\mathrm{V}_{\mathrm{CNT}} / \mathrm{V}_{\mathrm{M}}\right)$ for the $18 \% \mathrm{~V}_{\mathrm{CNT}}$, refer to Table 3. The stiffness increase follows a similar trend to previous CNT-glass 
hierarchical laminates prepared using EPD [12] in which $12 \% \mathrm{~V}_{\mathrm{CNT}} / \mathrm{V}_{\mathrm{M}}$ produced a $\mathrm{G}_{12}$ around 3.7 GPa compared to $4.4 \mathrm{GPa}$ at $16 \% \mathrm{~V}_{\mathrm{CNT}} / \mathrm{V}_{\mathrm{M}}\left(11 \% \mathrm{~V}_{\mathrm{CNT}}\right.$ in Fig. 6a). This suggests that, despite the different preparation methods, the CNTs become randomly oriented during the laminate fabrication. CNT-modified Nextel laminates have $\mathrm{G}_{12}$ values which are similar to those predicted (Fig. 6b) and also show considerable stiffness increases at $25 \% \mathrm{~V}_{\mathrm{CNT}} / \mathrm{V}_{\mathrm{M}}\left(7 \% \mathrm{~V}_{\mathrm{CNT}}\right.$ in Fig. $\left.6 \mathrm{~b}\right)$. The more than four-fold increase in $\mathrm{G}_{12}$ reflects effectiveness of the CNT addition. Since shear modulus is a matrix-dominated property, these results reflect the increase in shear modulus of the epoxy due to reinforcement by the CNTs.

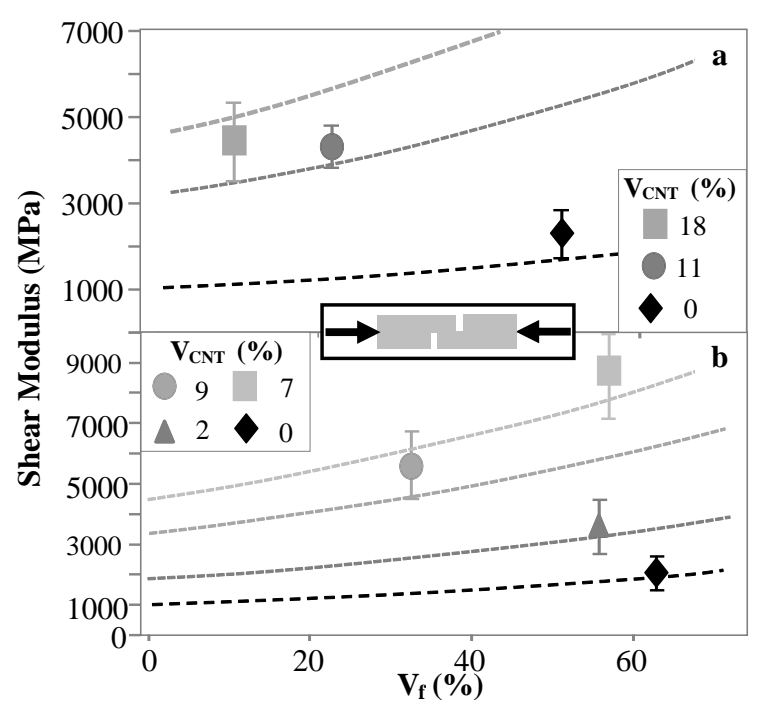

Fig.6. Shear modulus measured for the (a) Quartz and (b) Nextel/epoxy composites modified with CNTs as a function of fiber volume fraction. The dashed lines indicate the predicted modulus.

The shear strength for CNT-modified quartz laminates (Fig. 7) show a maximum increase of $80 \%$ from the baseline laminate, with a maximum strength similar to the shear adhesion test results in Fig. 3 and higher than IFSS values from CNTtreated single fiber tests between 17 and $24 \mathrm{MPa}$ [7]. The strength improvement is greater than the $15 \%$ increase in interlaminar shear strength (ILSS) reported for CNTquartz/epoxy laminates prepared by CVD [52] or the 33\% increase in ILSS reported for CNT/epoxy resin infused glass fabric [10]. 


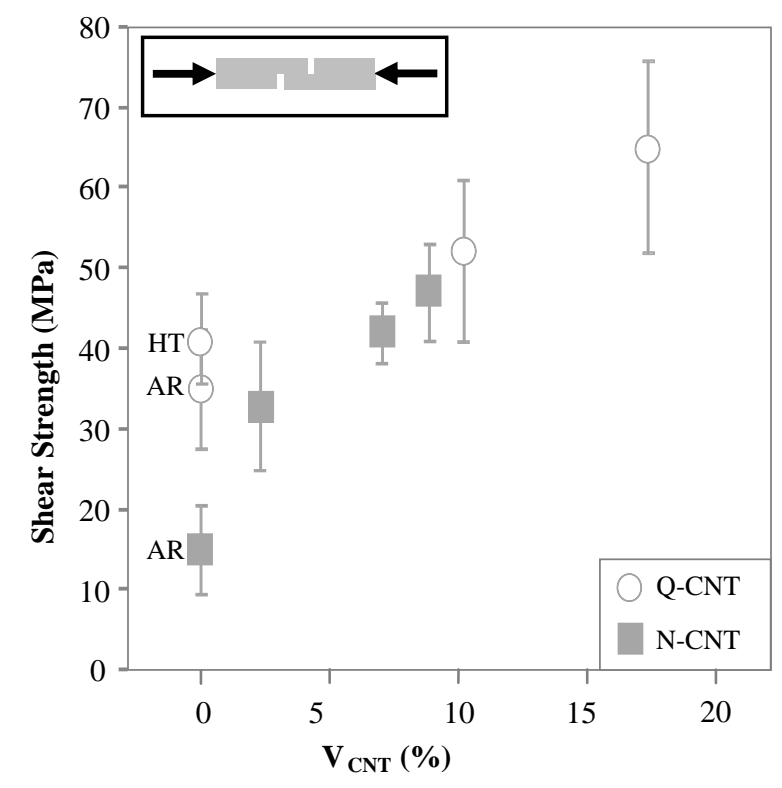

Fig. 7. Shear strength measured for the (a) Quartz and (b) Nextel composites as a function of CNT volume fraction. Strength for heat treated (HT) and as-received (AR) fabric without CNT treatment is also shown.

Analysis of the fracture surfaces (Fig. 8 ) reveal similar failure at the quartz fiber to CNT/resin interface as the adhesion tests (Fig. 4) and fracture through the CNT-rich matrix in the regions between the fibers. Notably, the quartz fibers show significant regions of etching (Fig. 8d) where the CNTs have sheared-off during fracture, which was not seen in the quartz-slide failure surfaces (Fig 4), confirming the damage caused by the CCVD growth is specific to the Astro-quartz fibers. The fracture for the $18 \%$ $\mathrm{V}_{\mathrm{CNT}}$ laminate (Fig. 8a\&c) shows more evidence of CNT pull-out than the $11 \% \mathrm{~V}_{\mathrm{CNT}}$ case (Fig. $8 \mathrm{~b}$ ) and poorer resin wetting in the higher $\% \mathrm{~V}_{\mathrm{CNT}}$ laminate may be the cause for the greater strength variability observed in Fig 7. The strength increase is similar to the CNT-glass and carbon/epoxy laminates prepared using EPD in which a PEI dendrimer was used to facilitate matrix toughening $[12,13]$. These results may suggest that the use of a toughening phase improves the ability of the CNTs to enhance strength in the high $\% \mathrm{~V}_{\mathrm{CNT}}$ matrix. 


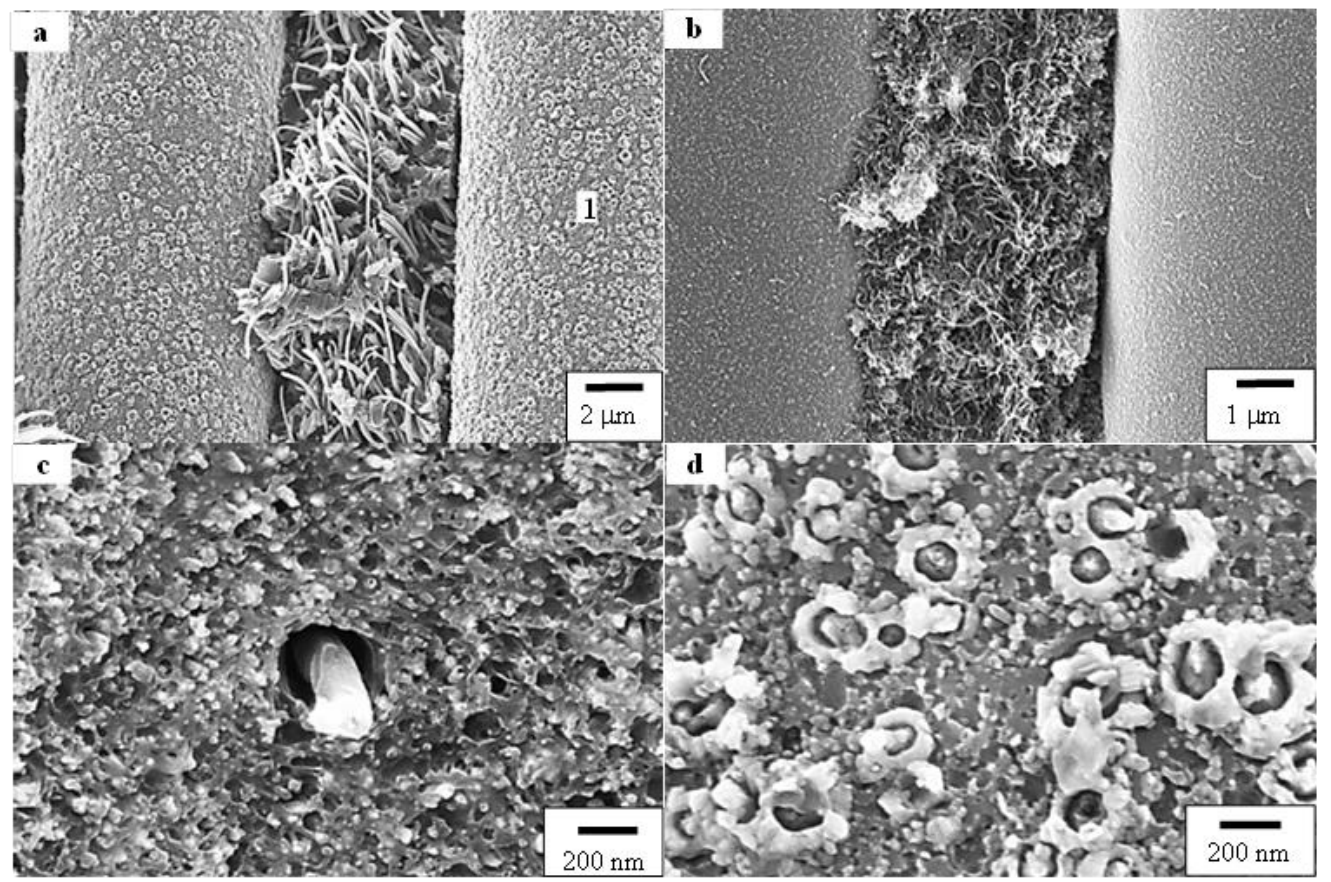

Fig.8 SEM images of failed in-plane shear specimens indicating CNT-Quartz/Epoxy with (a) $18 \% \mathrm{~V}_{\mathrm{CNT}}$ and (b) $11 \% \mathrm{~V}_{\mathrm{CNT}}$ showing (c) the CNT-matrix surface in contact with the fiber and (d) the fiber surface from point 1 in image (a)

The CNT-Nextel laminates show a similar trend in shear strength with $\% \mathrm{~V}_{\mathrm{CNT}}$ to the quartz laminates (Fig. 7). However, the baseline Nextel strength is quite low, below the values measured for the adhesion tests on the $\alpha$-alumina substrates in Fig. 3 (40 $\mathrm{MPa}$ ), and is lower than reported IFSS values measured from single-fiber tests for asreceived Nextel (38 MPa) or heat-treated Nextel fibers (26 MPa) [49]. An ILSS of 20 $\mathrm{MPa}$ for alumina/epoxy $(\mathrm{Al} / \mathrm{E})$ composite was previously reported [8], which is consistent with the current result, given double-notch shear strength is usually lower than values measured from short-beam shear (SBS) testing [53]. The shear strength value in Fig. 7 of $33 \mathrm{MPa}$ for $6 \% \mathrm{~V}_{\mathrm{CNT}} / \mathrm{V}_{\mathrm{M}}\left(2 \% \mathrm{~V}_{\mathrm{CNT}}\right.$ in Fig. 7$)$ is better than ILSS results reported for $\mathrm{CNT}$ modified $\mathrm{Al} / \mathrm{E}$ composites, which showed values around 34 $\mathrm{MPa}$ with a higher $\mathrm{V}_{\mathrm{CNT}} / \mathrm{V}_{\mathrm{M}}$ of $9 \%$ [8]. In the current tests there is more than 3-fold increase in the baseline strength for $9 \% \mathrm{~V}_{\mathrm{CNT}}\left(\mathrm{V}_{\mathrm{CNT}} / \mathrm{V}_{\mathrm{M}}\right.$ of $\left.17 \%\right)$ to $46 \mathrm{MPa}$. The lower strength for the $7 \% \mathrm{~V}_{\mathrm{CNT}}$ sample $\left(\mathrm{V}_{\mathrm{CNT}} / \mathrm{V}_{\mathrm{M}}\right.$ of $\left.25 \%\right)$ reflects sensitivity of the shear strength to $\mathrm{V}_{\mathrm{f}}$, with higher $\mathrm{V}_{\mathrm{f}}$ leading to lower strength. 
The failure surfaces for CNT-Nextel laminates in Fig. 9 are similar to the quartz images (Fig. 8), showing that failure starts at the fiber and CNT/resin interface, followed by fracture in the CNT-rich resin. The influence of the $\mathrm{V}_{\mathrm{f}}$ on the shear strength may be the result of the Nextel-fibers failing after the fiber/matrix debonding. As for the flexural strength (refer section 3.3.2), higher $V_{f}$ will increase the shear stress of the surrounding fibers after fracture, further initiating debonding. Previous work examining CNT-alumina/epoxy composites showed tougher epoxy enhanced mode I toughening effect of CNTs, leading to large fiber-matrix interface failure and increased fiber fracture [25], consistent with the current results. The higher shear strength with the CNT-quartz corresponds to much lower $\mathrm{V}_{\mathrm{f}}$ than the Nextel laminates, which would minimize the strength reduction caused by fiber fracture.

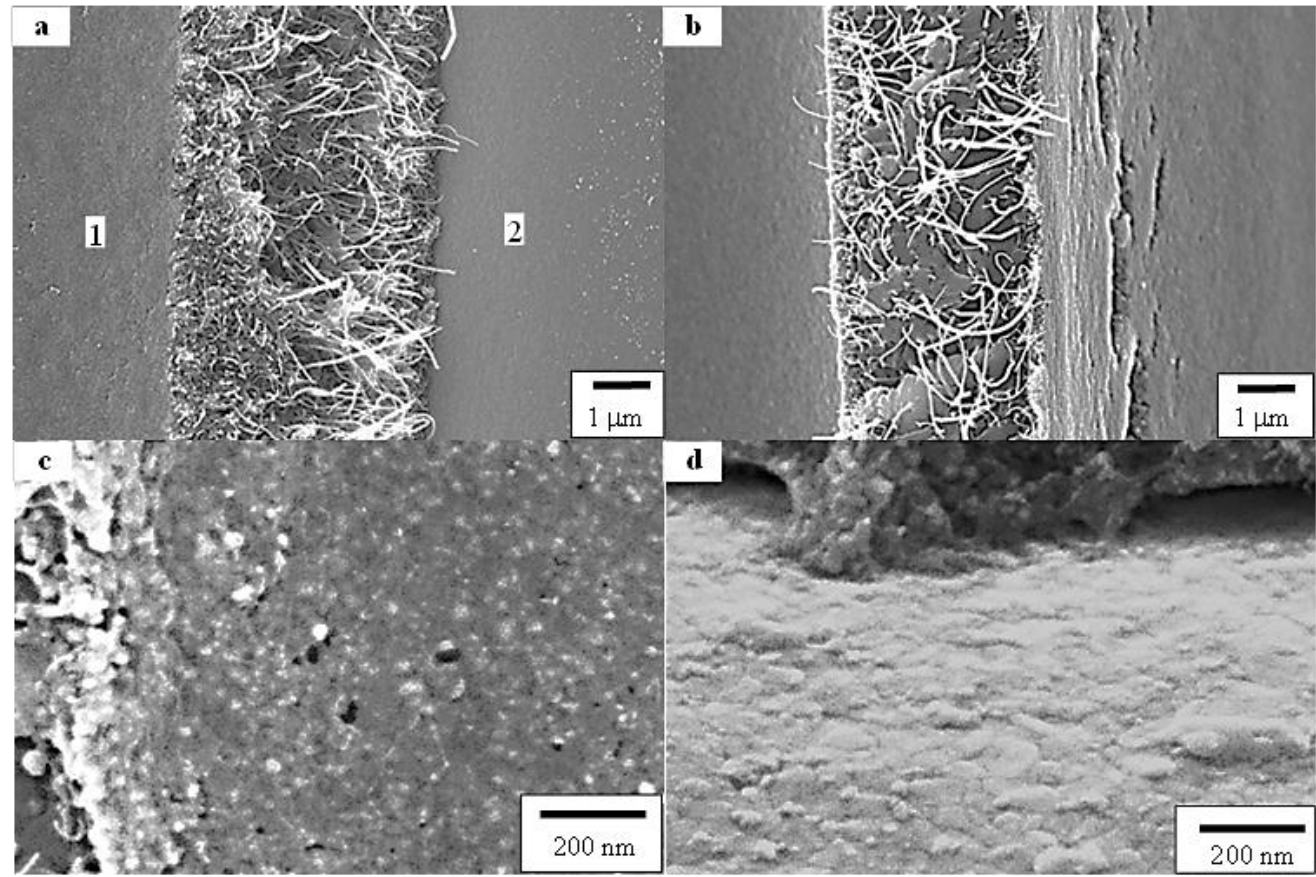

Fig. 9 SEM images of failed in-plane shear specimens indicating CNT-Nextel/epoxy with (a) $9 \% \mathrm{~V}_{\mathrm{CNT}}$ and (b) $2 \% \mathrm{~V}_{\mathrm{CNT}}$ showing (c) the matrix surface in contact with the fiber from point 1 in (a) and (d) the fiber surface from point 2 in image (a) 
Table 3: $\quad$ Compositions of the CNT-modified Quartz (Q) and Nextel (N)/epoxy laminates, indicating fibre, $\mathrm{V}_{\mathrm{f}}$, matrix, $\mathrm{V}_{\mathrm{M}}, \mathrm{CNT}, \mathrm{V}_{\mathrm{CNT}}$ and void, $\mathrm{V}_{\mathrm{v}}$ volume fractions.

\begin{tabular}{|c|c|c|c|c|c|c|c|c|c|c|}
\hline \multirow{2}{*}{ Laminate } & \multicolumn{2}{|l|}{$\mathbf{V}_{\mathbf{f}}$} & \multicolumn{2}{|l|}{$\mathbf{V}_{\mathbf{M}}$} & \multicolumn{2}{|c|}{$\mathrm{V}_{\mathrm{CNT}}$} & \multicolumn{2}{|l|}{$\mathbf{V}_{\mathbf{v}}$} & \multicolumn{2}{|c|}{$\mathbf{V}_{\mathrm{CNT}} / \mathbf{V}_{\mathrm{M}}$} \\
\hline & $\operatorname{avg}^{1}$ & conf. $^{2}$ & avg & conf. & avg & conf. & avg & conf. & avg & conf. \\
\hline Q (as-received) & 43.9 & 0.5 & 49.1 & 2.0 & --- & --- & 4.0 & 1.0 & --- & --- \\
\hline Q-HT (heat treated) & 50.9 & 0.7 & 47.6 & 0.5 & --- & --- & 1.5 & 0.5 & --- & --- \\
\hline Q-CNT-1 & 8.8 & 0.3 & 68.5 & 2.3 & 17.9 & 0.6 & 4.8 & 2.5 & 26.1 & 0.6 \\
\hline Q-CNT-2 & 20.3 & 0.4 & 64.5 & 2.9 & 10.5 & 0.2 & 4.7 & 2.8 & 16.3 & 0.8 \\
\hline $\mathrm{N}$ (as received) & 62.0 & 1.8 & 34.5 & 4.6 & --- & --- & 3.4 & 2.8 & --- & --- \\
\hline N-CNT-1 & 33.6 & 2.2 & 53.8 & 5.7 & 8.9 & 0.6 & 3.7 & 3.3 & 16.8 & 3.2 \\
\hline N-CNT-2 & 54.2 & 2.1 & 29.6 & 5.8 & 7.1 & 0.3 & 5.5 & 3.4 & 24.7 & 5.8 \\
\hline N-CNT-3 & 58.0 & 1.7 & 37.5 & 2.8 & 2.3 & 0.1 & 2.2 & 1.1 & 6.3 & 0.6 \\
\hline
\end{tabular}

\subsubsection{Flexure testing}

The flexural modulus for the CNT-modified quartz and Nextel/epoxy laminates is shown in Fig. 10. A typical example of the quartz fabric after 60 minutes CVD growth in Fig. S7 indicates the morphologies of the CNT-grafted fibers at different levels of magnification, prior to resin infusion. The modulus was modeled assuming 0/90 stacking sequence to represent the plain and satin-weave fabrics [54]. Each ply layer was modeled using the rule-of-mixtures (ROM) with the CNTs assumed to represent randomly-oriented discontinuous fibers based on the Halpin-Tsai equations [55]. The CNT aspect-ratio of 1000 (length $=30 \mu \mathrm{m}$, diameter $30 \mathrm{~nm}$ ) was based on SEM measurements (Fig S6 and S7) and assumed an effective reinforcing modulus ( $\left.\mathrm{E}_{\mathrm{ERM}}\right)$ of $95 \mathrm{GPa}$. The E ERM was calculated by measuring the waviness of the CNTs (Fig. S6 and S7), which provided an amplitude on wavelength (a/ $\lambda$ ) of approximately 0.2 . By 
assuming the CNTs had an average modulus of $450 \mathrm{GPa}[56-58]$ and the modulus ratio of the CNTs to matrix was 200, then the $\mathrm{E}_{\mathrm{ERM}}$ was determined from the previous analysis by Fisher et al [58]. Fiber properties were taken from the literature [27, 29], with the quartz modulus ( $72 \mathrm{GPa}$ ) reduced by the factor measured in Fig. 1 for CNT treatments (44 GPa). All laminate compositions are detailed in Table 3. The quartz-heat treated samples and the $11 \%$ volume fraction $\mathrm{CNT}\left(\mathrm{V}_{\mathrm{CNT}}\right)$ laminate are slightly less than the predicted stiffness, but the $18 \% \mathrm{~V}_{\mathrm{CNT}}$ laminate is clearly less than expected (Fig. 10a). This may indicate that the longest treatment times increase the sensitivity of the fibers to bending stresses, leading to progressive failure of the more damaged fibers and the reduction in the measured modulus. The Nextel laminates appear to have stiffness a little below that predicted (Fig. 10b) and indicate relative insensitivity to the addition of CNTs, which may be expected based on the high stiffness of the $\alpha$-alumina.

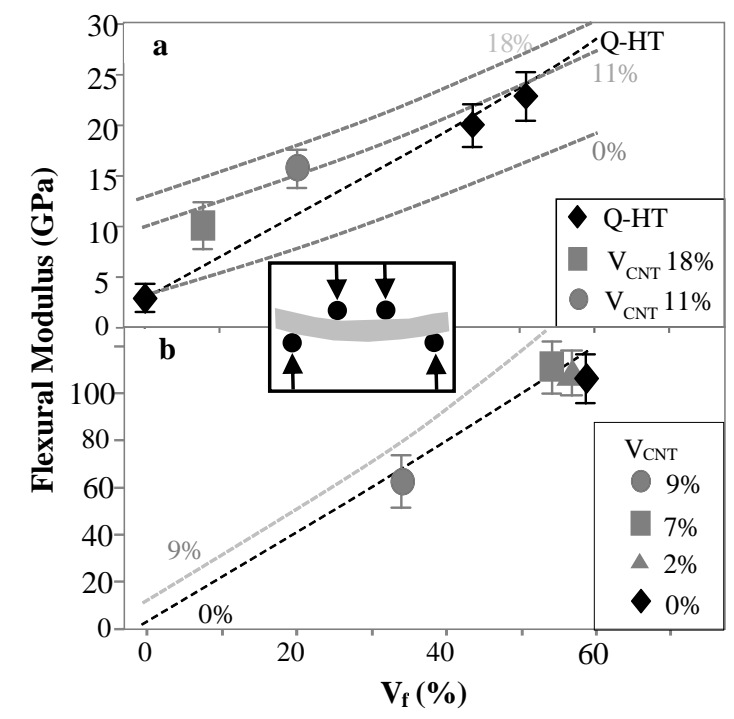

Fig. 10. Flexural modulus measured for the (a) quartz-epoxy (Q) and (b) Nextel-epoxy (N) composites modified with CNTs as a function of $\mathrm{V}_{\mathrm{f}}$. The dashed lines represent the rule-ofmixtures prediction for the CNT (grey) and heat-treated (black) fibers.

An additional factor that may affect stiffness is caused by the influence of CNT growth on the fiber geometry. As the CNTs grow the fiber tows expand, which leads to increased fiber waviness (Fig. S8). The $18 \% \mathrm{~V}_{\mathrm{CNT}}$ quartz laminate in Fig. 10a corresponds to 60 minutes growth, which produces more fiber waviness than the $11 \%$ $\mathrm{V}_{\mathrm{CNT}}$ laminate produced from a shorter growth time. Because the CNT treated quartz 
laminates have higher $\mathrm{V}_{\mathrm{CNT}}$ compared to Nextel laminates and the Nextel laminates use a satin-weave fabric, the CNT growth will not lead to the same level of tow expansion and associated fiber waviness. However, there will still be an increased fiber waviness that will reduce the stiffness in the CNT treated Nextel laminates that is not allowed for in the straight forward ROM calculations.

The flexure strength (Fig. 11a) for the quartz-CNT laminates was predicted using the theoretical modulus (Fig. 10a) and a failure strain of 1.5\%, measured from the fiber-bundle test (Figs. 1-2). The CNT treatments have strengths below those predicted, suggesting the fiber's maximum tensile strain was not reached. Failure of the quartz laminates typically occurred on the compression side under the loading point due to fiber fracture. The fiber waviness, discussed above, may lead to microbuckling and the lower strength caused by compression induced failure and would not be allowed for in the failure strain model, where tensile failure would be expected.

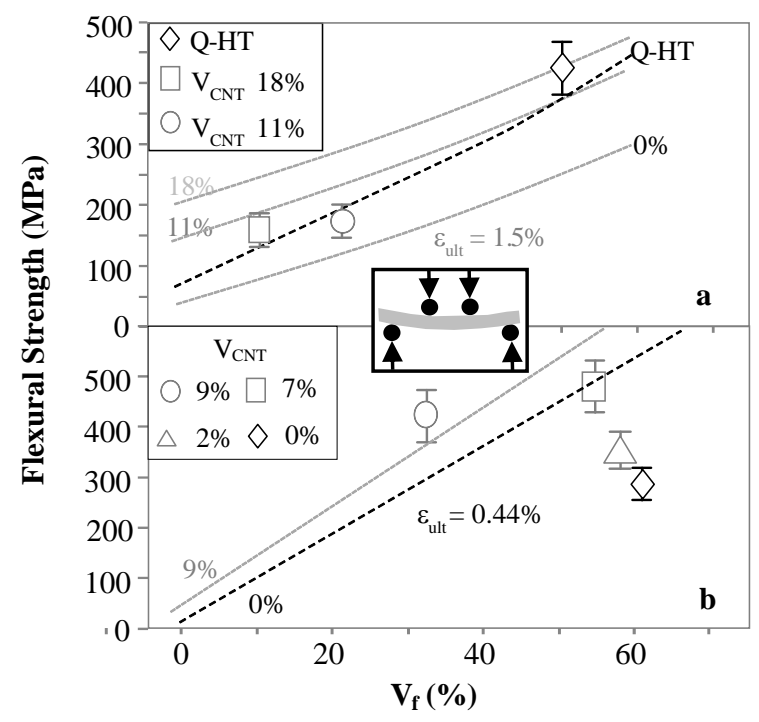

Fig. 11. Flexural strength of the CNT treated (a) quartz (Q) and (b) Nextel (N) epoxy laminates as a function of $\mathrm{V}_{\mathrm{f}}$. The dashed lines represent the strain-to-failure prediction for the CNT (grey) and heat-treated (black) fibers.

The CNT-Nextel laminates (Fig. 11b) all exhibit strength which increases at approximately $25 \mathrm{MPa}$ for each percentage increase in $\mathrm{V}_{\mathrm{CNT}}$ using a $0.44 \%$ failure strain measured from the fiber tests (Fig. 1). The $9 \%$ and $7 \% \mathrm{~V}_{\mathrm{CNT}}$ laminates are close to predicted strengths, but the measured strength is quite low for the $0 \%$ and $2 \% \mathrm{CNT}$ 
samples where the fiber volume fraction $\left(\mathrm{V}_{\mathrm{f}}\right)$ is higher. Work on failure mechanisms of Nextel fibers embedded in epoxy resin has shown small inter-fiber distances lead to stress concentrations around 1.2 [59]. As a fiber fractures the neighboring fiber also sees an instantaneous dynamic stress concentration that may cause adjacent fiber fracture. The increased inter-fiber spacing at lower fiber volume fractions will reduce this stress concentration effect, resulting in strengths closer to predicted values. Nextel samples exhibited a combination of tow fracture on the compression side under the loading point and delamination between the first and second warp and weft layers. This failure process also suggests that the presence of the CNT reinforcement may assist in reducing the interply delamination that occurs with the compression induced micro-buckling and fiber fracture.

It should be noted that interlaminar shear (ILS) properties may also play an important role in the flexural strength of the laminates. An often used test to examine the ILS strength of laminates is the short beam shear test $[8,25]$, however, in the current studies the variable $\mathrm{V}_{\mathrm{f}}$ of the laminates and the brittle nature of the fibers would have made this test difficult to apply and produce quantitatively comparable results. Future work of the hierarchical composites should examine the ILS properties to establish their contribution to laminate fracture mechanisms.

\subsection{Electrical properties and electrical-mechanical coupling}

Figure 12 shows the in-plane electrical conductivity of the CNT-modified quartz and Nextel laminates as a function of CNT concentration. The electrical conductivity with increasing CNT concentration follows the power-law trend predicted by percolation theory. The quartz and Nextel laminates have similar electrical conductivities measured in both in-plane directions, which may be expected given CNTs are grown directly onto plane and satin-weave fabrics. The electrical conductivities are higher than 1.2-1.4 S/cm at 2-3\% $\mathrm{V}_{\mathrm{CNT}}$ reported for alumina/epoxy composites $[8,19]$ and significantly higher than $0.01 \mathrm{~S} / \mathrm{cm}$ reported for CNT-modified quartz/epoxy laminates prepared by CVD [52]. Interestingly, in aligned-polymer nanocomposites with $20 \% \mathrm{~V}_{\mathrm{CNT}} / \mathrm{V}_{\mathrm{M}}$ the conductivity was about $0.5 \mathrm{~S} / \mathrm{cm}$ [60]. The high in-plane electrical conductivity of the composites with CCVD grown CNTs on the surfaces indicate that there is possibly another conducting mechanism that influences the overall electrical. The nanotube-fiber interfaces show a high concentration of 
catalyst nanoparticles. These metallic-iron nanoparticles that form along the fiber (shown in Fig. 4d), may form an additional conducting pathway that contributes to the overall composite electrical conductivity. Randomly oriented nanotube composites typically only have electrical conductivities the range of $0.1 \mathrm{~S} / \mathrm{cm}$ above the percolation threshold $[11,61]$ and glass-epoxy composites with EPD deposited CNT layers exhibited conductivity around $0.05 \mathrm{~S} / \mathrm{cm}[12]$. For the composites produced using EPD, the conductivity is further reduced by surface functionalization with PEI, resulting in a polymer film between contacting CNTs.

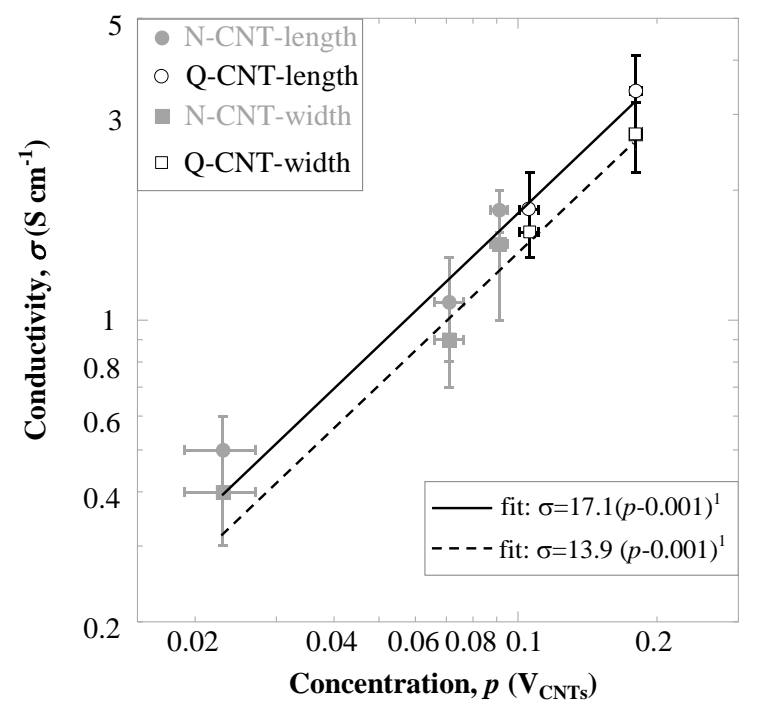

Fig. 12 Conductivity of the epoxy and CNT-treated Nextel (N) and quartz (Q) laminates as a function of the CNT concentration in the fabric warp (length) and weft (width) directions

Figure 13 shows the normalized in-plane electrical resistance change as a function of maximum tensile strain under flexural loading. The resistance-strain behavior for the Nextel laminates (Fig. 13a) shows that at low strains there is relatively small sensitivity to bending. The laminate can be thought of as resistors acting in parallel. Since the strain varies linearly from tension to compression across the height of the laminate the increase in resistance due to tensile strain is balanced by a decrease in resistance due to compressive strains. If the resistance change-strain relationship is the same in both tension and compression the overall resistance will be slightly negative, owing to the lower resistor dominating in a parallel circuit. The laminates higher 
volume fractions of carbon nanotubes (7\% and $9 \%)$ show a slightly negative slope of the normalized resistance change-strain curve. At the lower nanotube concentration of 2 $\%$ in the Nextel laminates the slope is slightly positive at low strains, indicating that there is a larger tensile resistance change-strain relationship as compared to the resistance change in compression. This is consistent with recent reports showing that there is less piezoresistive strain sensitivity in compression as compared to tension [62]. At higher strains there is a significant increase in the slopes of all of the curves. In addition, after the specimens are no longer linear elastic, the resistance change increases significantly resulting from the formation of damage in the specimen, which permanently severs conducting pathways. The resistance-strain behavior follows a similar trend in the quartz laminates, as shown in Figure 13b. The laminate with the lower CNT volume fraction shows a larger resistance change under bending loads. For the quartz laminates the flexural stress-strain behavior is completely linear up to fracture, with no inelastic behavior, as observed in the Nextel laminates. This is likely due to the significant reduction in the tensile strength of the quartz fibers subjected to the CCVD process. 

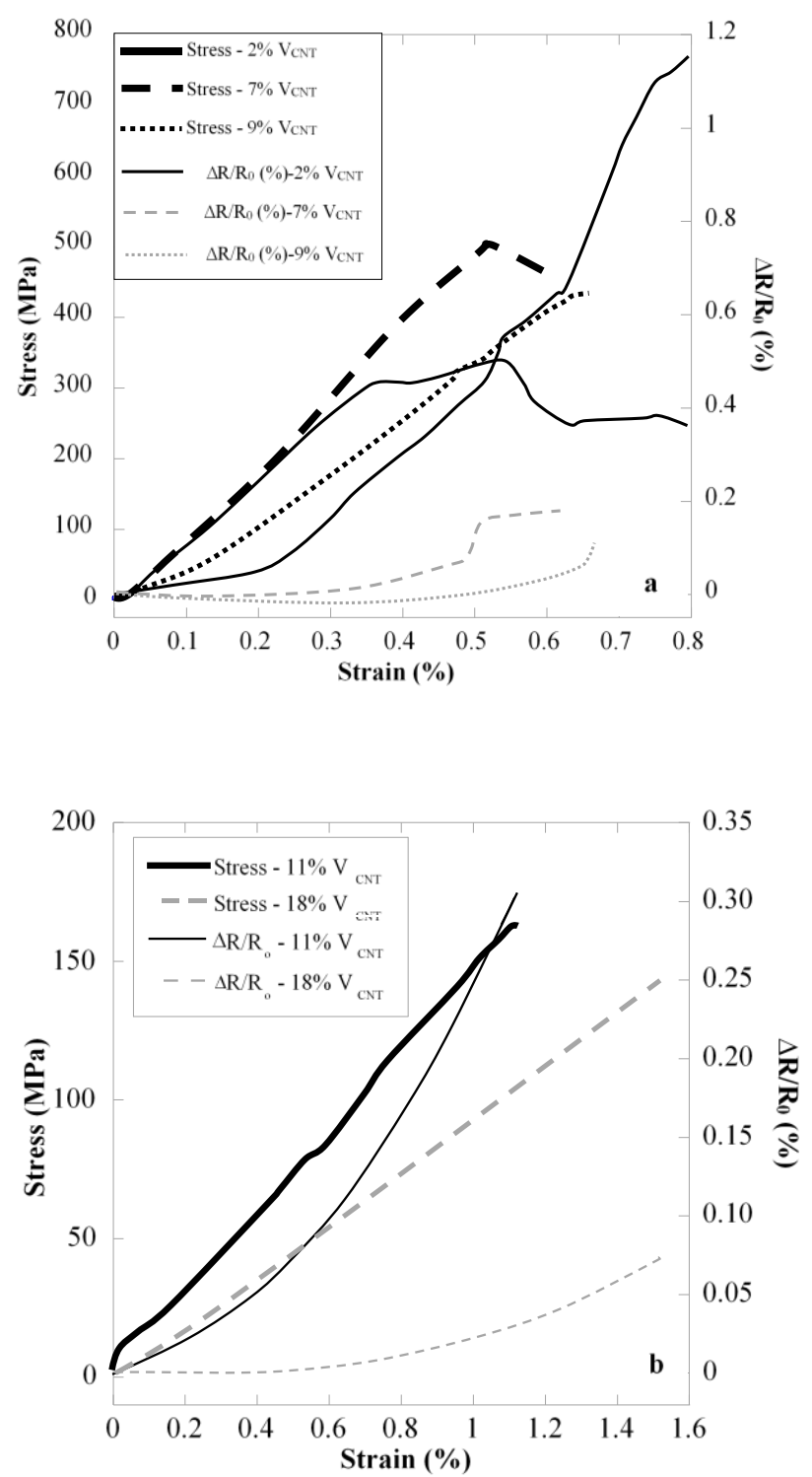

Fig. 13. Stress and resistance change with maximum tensile strain under flexural loading for CNT-treated (a) Nextel and (b) quartz-fiber composite laminates.

It is instructive to look at the gradient of the resistance change with applied strain. Figure 14 shows the derivative of the resistance-strain curves in the linear elastic regions in Figure 13. For the quartz laminates the resistance change gradient is linear and likely indicates that there is a difference in the resistance-strain behavior in tension and compression. The derivative of the Nextel laminates shows a sharp increase just before initial failure. Since the Nextel fibers retain more of their strength during the CCVD process, the laminates reach much higher stresses under flexure and it is likely that some damage accumulates in the form of transverse microcracks and fiber/matrix 
debonding before the peak failure stress is reached. These microcracks will result in a much higher resistance change on the tensile side of the laminate. This abrupt change in the resistance change gradient just prior to failure for the Nextel laminates is an early indicator of impending failure.

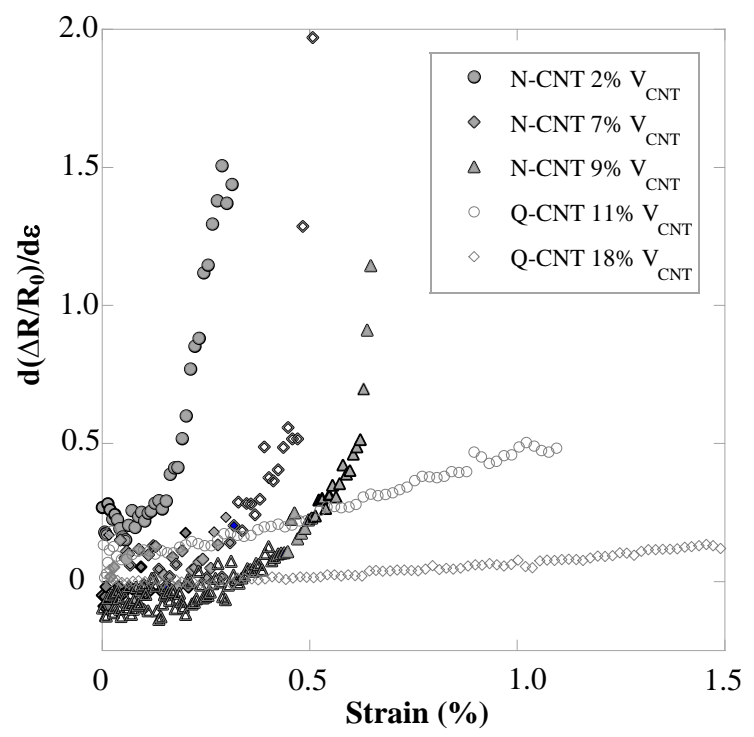

Fig. 14. The normalized resistance change gradient with maximum tensile strain of the CNT treated quartz $(\mathrm{Q})$ and Nextel $(\mathrm{N})$ laminates under flexural loading.

\section{Conclusions}

The CCVD process has been scaled-up to produce macroscopic sheets of woven alumina and quartz fibers with CNTs grown on their surfaces for producing novel hierarchically structured composites with high-volume fractions of CNTs. The shear strength of a nano-modified epoxy resin bonded to quartz or alumina can be increased significantly by growing CNT layers prior to infusion of the polymer. Oxygen plasma treatment of the CNT films grown on quartz improves the resin wettability and leads to $30 \%$ increase in strength. The failure surfaces indicate that fracture at the CNT-infused film and substrate interface dominates. CNT growth onto quartz and alumina woven fabrics also leads to a significant increase in the composite in-plane shear strength. The composite shear strength is a direct function of the CNT volume fraction and similar increases are observed for both quartz and alumina composites. As with the films, the initial fracture occurs at the fiber/CNT interface, leading to failure. Observed matrix 
cavitation and CNT pull-out suggest the nanophase thermoplastic contributes to the CNT/epoxy toughness and that the matrix does not limit the composite strength. Further strength improvements would require improved adhesion between the CNTs and fiber.

As compared to hierarchical composites produced with the EPD method, the shear strength and stiffness increases by a similar amount with CCVD growth of CNTs. However, a major disadvantage of the CCVD process is that fiber degradation occurs, particularly with the quartz laminate. The EPD-processed composites exhibit a more desirable fracture within the CNT-rich interphase region, away from the fiber/matrix interface. This may suggest that improved strength using EPD could be achieved with higher aspect-ratio CNTs or CNT orientation which facilitates the higher packing density, both attributes offered by the CCVD approach.

The hierarchical composites produced by the CCVD method show very high inplane electrical conductivity, which is believed to result from the high density of CNTs grown radially from the fibers, with the interconnecting metallic iron-nanoparticles along the fiber interface providing a high conductivity path. The integration of CNTs into the non-conducting quartz and alumina fibers imparts a sensing functionality to the composite, where the piezo-resistive response can be utilized to detect deformation and also damage initiation. The sensing response is influenced by the CNT-volume fraction. In particular, the alumina composites show a sharp increase in resistance change gradient with flexural strain just prior to composite fracture. The resistance change is likely influenced by the initiation of micro cracks in the polymer matrix, and holds promise for detecting the impending failure.

\section{Acknowledgements}

The author from the University of Delaware gratefully acknowledges support of the US National Science Foundation (Grant \#: 1254540_Dr. Mary Toney, Program Director)

\section{Appendix A. Supplementary data}

Reactor design, coated-fabric image, nanophase-toughened epoxy fracture images, XPS spectra for functionalized CNTs and CNT images for CCVD growth on quartz and alumina. This material is available free of charge via the Internet.

\section{References}


1. Pandey G, Thostenson ET, Carbon nanotube-based multifunctional polymer nanocomposites. Polym. Rev. 52 (2012) 355-416.

2. Diez-Pascual AM, Gonzalez-Dominguez JM, Martinez MT, Gomez-Fatou MA. Poly(ether ether ketone)-based hierarchical composites for tribological applications. Chem. Eng. J. 218 (2013) 285-294.

3. Qian H, Greenhalgh ES, Shaffer MS, Bismarck A. Carbon nanotube-based hierarchical composites: a review. J. Mat. Chem. 20 (2010) 4751-4762.

4. Drzal LT, Madhukar M. Fibre-matrix adhesion and its relationship to composite mechanical properties. J. Mater. Sci. 28 (1993) 569-610.

5. Kamae T, Drzal LT. Carbon fiber/epoxy composite property enhancement through incorporation of carbon nanotubes at the fiber-matrix interphase-Part I: The development of carbon nanotube coated carbon fibers and the evaluation of their adhesion. Compos. Part A: Appl. S. 43 (2012) 1569-1577.

6. Thostenson E, Li W, Wang D, Ren Z, Chou T. Carbon nanotube/carbon fiber hybrid multiscale composites. J. Appl. Phys. 91 (2002) 6034-6037.

7. Qian H, Bismarck A, Greenhalgh ES, Shaffer MSP. Carbon nanotube grafted silica fibres: Characterising the interface at the single fibre level, Compos. Sci. Technol. 70 (2010) 393-399.

8. Garcia EJ, Wardle BL, John Hart A, Yamamoto N. Fabrication and multifunctional properties of a hybrid laminate with aligned carbon nanotubes grown In Situ. Compos Sci Technol. 68 (2008) 2034-41.

9. Kim H, Oh E, Hahn HT, Lee KH. Enhancement of fracture toughness of hierarchical carbon fiber composites via improved adhesion between carbon nanotubes and carbon fibers. Compos Part A Appl Sci Manuf. 71 (2015) 72-83.

10. Fan Z, Santare MH, Advani SG. Interlaminar shear strength of glass fiber reinforced epoxy composites enhanced with multi-walled carbon nanotubes. Compos Part A Appl Sci Manuf. 39 (2008) 540-54.

11. Thostenson ET, Chou T-W. Processing-structure-multifunctional property relationship in carbon nanotube/epoxy composites. Carbon 44 (2006) 3022-9.

12. An Q, Rider AN, Thostenson ET, Hierarchical composite structures prepared by electrophoretic deposition of carbon nanotubes onto glass fibers. ACS Appl. Mater. Inter. 5 (2013) 2022-2032.

13. An Q, Rider AN, Thostenson ET. Electrophoretic deposition of carbon nanotubes onto carbonfiber fabric for production of carbon/epoxy composites with improved mechanical properties. Carbon 50 (2012) 4130-4143. 
14. Zhang H, Liu Y, Kuwata M, Bilotti E, Peijs T. Improved fracture toughness and integrated damage sensing capability by spray coated CNTs on carbon fibre prepreg. Compos Part A Appl Sci Manuf. 70 (2015) 102-10.

15. Rider AN, An Q, Brack N, Thostenson ET. Polymer nanocomposite - fiber model interphases: Influence of processing and interface chemistry on mechanical performance. Chemical Engineering Journal. 269 (2015) 121-34.

16. Zhang Q, Liu J, Sager R, Dai L, Baur J. Hierarchical composites of carbon nanotubes on carbon fiber: Influence of growth condition on fiber tensile properties. Compos. Sci. Technol. 69 (2009) 594-601.

17. Kim KJ, Yu W, Youk JH, Lee J. Degradation and healing mechanisms of carbon fibers during the catalytic growth of carbon nanotubes on their surfaces,. ACS Appl. Mater. Inter. 4 (2012) 2250-2258.

18. Steiner SA, Li R, Wardle BL. Circumventing the mechanochemical origins of strength loss in the synthesis of hierarchical carbon fibers. ACS Appl Mater Interfaces. 5 (2013) 4892-903.

19. Yamamoto N, Guzman de Villoria R, Wardle BL. Electrical and thermal property enhancement of fiber-reinforced polymer laminate composites through controlled implementation of multi-walled carbon nanotubes. Compos Sci Technol. 72 (2012) 2009-15.

20. Díez-Pascual AM, Ashrafi B, Naffakh M, González-Domínguez JM, Johnston A, Simard B, et al. Influence of carbon nanotubes on the thermal, electrical and mechanical properties of poly(ether ether ketone)/glass fiber laminates. Carbon. 49 (2011) 2817-33.

21. Rider AN., Yeo E.-Y., Brack N., Halstead BW., Pigram PJ. Modification of quartz fabric with multi-walled carbon nanotubes for multifunctional polymer composites. Ceramic Transactions 208 (2009) $59-70$.

22. Thostenson ET, Chou T. Carbon nanotube networks: sensing of distributed strain and damage for life prediction and self-healing. Adv. Mater. 18 (2006) 2837-2841.

23 Schumacher T, Thostenson ET, Development of structural carbon nanotube-based sensing composites for concrete structures. Journal of Intelligent Material Systems and Structure. 25 (2014) 13311339.

24 Gallo, GJ, Thostenson, ET. Electrical characterization and modeling of carbon nanotube and carbon fiber self-sensing composites for enhanced sensing of microcracks. Materials Today Communications. 3 (2015) 17-26.

25. Wicks SS, Wang W, Williams MR, Wardle BL. Multi-scale interlaminar fracture mechanisms in woven composite laminates reinforced with aligned carbon nanotubes. Compos Sci Technol. 100 (2014) $128-35$.

26. Astroquartz® Product Manual, JPS Composite Materials, PO Box 242 Slater Road Slater, SC 29683, jpscm.com. 
27. Wallenberger FT, Bingham PA. Fiberglass and glass technology: Energy-friendly compositions and applications: Springer US; 2010. p. 3-22.

28. $3 \mathrm{M} \mathrm{Nextel}^{\mathrm{TM}}$ Ceramic Textiles Technical Notebook, 3M Company, St Paul, Minnesota.

29. Wilson DM, Visser LR. High performance oxide fibers for metal and ceramic composites. Compos. Part A: Appl. S. 32 (2001) 1143-53.

30. Ritzenthaler S, Court F, Girard-Reydet E, Leibler L, Pascault JP. ABC triblock copolymers/epoxy-diamine blends. 2. Parameters controlling the morphologies and properties. Macromolecules. 36 (2003) 118-126.

31 Kappen P, Halstead B, Rider AN, Pigram PJ, Brack N. Multi-walled carbon nanotubes grown from chemical vapor: Links between atomic near range order and growth parameters. Journal of Physical Chemistry C. 113 (2009) 4307-4314.

32. Halstead BW, Brack N, Rider AN, Yeo E, Pigram PJ, Glaisher R, et al. Scaled-up production of multi-walled carbon nanotubes using catalytic chemical vapour deposition. Proceedings of the 2006 International Conference on Nanoscience and Nanotechnology, ICONN, Brisbane: 2006, p. 146-50.

33. Li C-T, Langley NR. Improvement in fiber testing of high-modulus single-filament materials. Journal of the American Ceramic Society. 68 (1985) C-202-C-204.

34. Coleman BD. On the strength of classical fibres and fibre bundles. J Mech Phys Solids. 7 (1958) 60-70.

35. R'Mili M, Bouchaour T, Merle P. Estimation of Weibull parameters from loose-bundle tests. Compos Sci Technol. 56 (1996) 831-4.

36. ASTM D6272-02: Standard test method for flexural properties of unreinforced and reinforced plastics and electrical insulating materials by four-point bending; American Society for Testing and Materials, West Conshohocken, PA., 2002.

37. ASTM D3846: Standard test method for in-plane shear strength of reinforced plastics; American Society for Testing and Materials, West Conshohocken, PA., 2002.

38. ASTM D1505: Test method for density of plastics by the density-gradient technique; American Society for Testing and Materials, West Conshohocken, PA., 2003.

39. ASTM D257: Standard Test Methods for DC Resistance or Conductance of Insulating Materials; American Society for Testing and Materials, West Conshohocken, PA., 2006.

40. Hunt CP, Seah MP. Characterization of a high depth-resolution tantalum pentoxide sputter profiling reference material. Surface and Interface Analysis. 5 (1983) 199-209. 
41. Bashar MT, Sundararaj U, Mertiny P. Morphology and mechanical properties of nanostructured acrylic tri-block-copolymer modified epoxy. Polym Eng Sci. 54 (2014) 1047-55.

42. Plonka R, Mäder E, Gao SL, Bellmann C, Dutschk V, Zhandarov S. Adhesion of epoxy/glass fibre composites influenced by aging effects on sizings. Compos. Part A: Appl. S. 35 (2004) 1207-16.

43. Gao S-L, Mäder E, Abdkader A, Offermann P. Sizings on Alkali-Resistant Glass Fibers: Environmental Effects on Mechanical Properties. Langmuir. 19 (2003) 2496-506.

44. Schutte CL, McDonough W, Shioya M, McAuliffe M, Greenwood M. The use of a single-fibre fragmentation test to study environmental durability of interfaces/interphases between DGEBA/mPDA epoxy and glass fibre: the effect of moisture. Composites. 25 (1994) 617-24.

45. Bittencourt C, Navio C, Nicolay A, Ruelle B, Godfroid T, Snyders R, et al. Atomic Oxygen Functionalization of Vertically Aligned Carbon Nanotubes. The Journal of Physical Chemistry C. 115 (2011) 20412-8.

46. Colomer JF, Ruelle B, Moreau N, Lucas S, Snyders R, Godfroid T, et al. Vertically aligned carbon nanotubes: Synthesis and atomic oxygen functionalization. Surface and Coatings Technology. 205 (2011); Supplement 2:S592-S596.

47. Jeong JY, Park J, Henins I, Babayan SE, Tu VJ, Selwyn GS, et al. Reaction chemistry in the afterglow of an oxygen-helium, atmospheric-pressure plasma. J Phys Chem A. 104 (2000) 8027-32.

48. Gonzalez Ii E, Barankin MD, Guschl PC, Hicks RF. Remote atmospheric-pressure plasma activation of the surfaces of polyethylene terephthalate and polyethylene naphthalate. Langmuir. 24 (2008) 12636-43.

49. Yallee RB, Young RJ. Micromechanics of fibre fragmentation in model epoxy composites reinforced with $\alpha$-alumina fibres. Compos Part A Appl Sci Manuf. 29 (1998) 1353-62.

50. Barbero EJ. Introduction to Composite Materials Design, Second Edition: Taylor \& Francis; 2010. p. 103-105.

51. Yallee RB, Young RJ. Evaluation of interface fracture energy for single-fibre composites. Compos Sci Technol. 58 (1998) 1907-16.

52. Jin L, Zhang L, Su D, Li C. Direct growth of aligned carbon nanotubes on quartz fibers for structural epoxy composites. Ind Eng Chem Res. 51 (2012) 4927-33.

53. Almeida Jr JHS, Angrizani CC, Botelho EC, Amico SC. Effect of fiber orientation on the shear behavior of glass fiber/epoxy composites. Materials \& Design. 65 (2015) 789-95.

54. Gibson RF. Principles of Composite Material Mechanics, Second Edition: Taylor \& Francis; 2007. p. 261-273. 
55. Mallick PK. Fiber-Reinforced Composites: Materials, Manufacturing, and Design, Third Edition: CRC Press; 2007. p. 161-164.

56. Löffler M, Weissker U, Mühl T, Gemming T, Büchner B. Robust determination of Young's modulus of individual carbon nanotubes by quasi-static interaction with Lorentz forces. Ultramicroscopy. 111 (2011) 155-8.

57. Salvetat JP, Kulik AJ, Bonard JM, Briggs GAD, Stöckli T, Méténier K, et al. Elastic modulus of ordered and disordered multiwalled carbon nanotubes. Adv Mater. 11 (1999) 161-5.

58. Fisher FT, Bradshaw RD, Brinson LC. Effects of nanotube waviness on the modulus of nanotube-reinforced polymers. Appl Phys Lett. 80 (2002) 4647-9.

59. Mahiou H, Beakou A, Young RJ. Investigation into stress transfer characteristics in aluminafibre/epoxy model composites through the use of fluorescence spectroscopy. Journal of Materials Science. 34 (1999) 6069-80.

60. Cebeci H, Villoria RG, Hart AJ, Wardle BL. Multifunctional properties of high volume fraction aligned carbon nanotube polymer composites with controlled morphology. Compos Sci Technol. 69 (2009) 2649-56.

61. Kim YJ; Shin TS; Choi HD, Kwon JH, Chung YC; Yoon, HG. Carbon. 43 (2005) 23-30.

62. Ku-Herrera, JJ, Aviles F. Cyclic tension and compression piezoresistivity of carbon nanotube/vinyl ester composites in the elastic and plastic regimes. Carbon. 50 (2012). 2592-2598. 